\title{
Two-dimensional material-based bionano platforms to control mesenchymal stem cell differentiation
}

\author{
Ee-Seul Kang ${ }^{1 \dagger}$, Da-Seul Kim $^{1 \dagger}$, Intan Rosalina Suhito ${ }^{1 \dagger}$, Wanhee Lee ${ }^{1 \dagger}$, Inbeom Song ${ }^{1}$ and Tae-Hyung Kim ${ }^{1,2^{*}}$
}

\begin{abstract}
Background: In the past decade, stem cells, with their ability to differentiate into various types of cells, have been proven to be resourceful in regenerative medicine and tissue engineering. Despite the ability to repair damaged parts of organs and tissues, the use of stem cells still entails several limitations, such as low differentiation efficiency and difficulties in guiding differentiation. To address these limitations, nanotechnology approaches have been recently implemented in stem cell research. It has been discovered that stem cells, in combination with carbon-based functional materials, show enhanced regenerative performances in varying biophysical conditions. In particular, several studies have reported solutions to the conventional quandaries in biomedical engineering, using synergetic effects of nanohybrid materials, as well as further development of technologies to recover from diverse health conditions such as bone fracture and strokes.
\end{abstract}

Main text: In this review, we discuss several prior studies regarding the application of various nanomaterials in controlling the behavior of stem cells. We focus on the potential of different types of nanomaterials, such as two-dimensional materials, gold nanoparticles, and three-dimensional nanohybrid composites, to control the differentiation of human mesenchymal stem cells (hMSCs). These materials have been found to affect stem cell functions via the adsorption of growth/differentiation factors on the surfaces of nanomaterials and the activation of signaling pathways that are mostly related to cell adhesion and differentiation (e.g., FAK, Smad, Erk, and Wnt).

Conclusion: Controlling stem cell differentiation using biophysical factors, especially the use of nanohybrid materials to functionalize underlying substrates wherein the cells attach and grow, is a promising strategy to achieve cells of interest in a highly efficient manner. We hope that this review will facilitate the use of other types of newly discovered and/or synthesized nanomaterials (e.g., metal transition dichalcogenides, non-toxic quantum dots, and metal oxide frameworks) for stem cell-based regenerative therapies.

Keywords: Graphene, Two-dimensional materials, Gold nanoparticles, Three-dimensional graphene composites, Human mesenchymal stem cell, Differentiation

\section{Background}

Recently, a wide variety of stem cells have been investigated for their extensive utility in biomedical applications, owing to their abilities to differentiate into specific cell lineages, and to generate more stem cells. Mesenchymal

\footnotetext{
* Correspondence: thkim0512@cau.ac.kr; https://sites.google.

com/site/causnel/

${ }^{\dagger}$ Equal contributors

'School of Integrative Engineering, Chung-Ang University, 84 Heukseok-ro, Dongjak-gu, Seoul 06974, Republic of Korea

${ }^{2}$ Integrative Research Center for Two-Dimensional Functional Materials, Institute of Interdisciplinary Convergence Research, Chung-Ang University, Seoul 06974, Republic of Korea
}

stem cells (MSCs), which are multipotent stromal stem cells, have been extensively investigated for their accessibility, versatility, and low risk of teratoma formation. Their multipotency allows them to differentiate into several specific cell types (e.g. adipocytes, osteoblasts, chondrocytes), to form fat [1], bone [2], and cartilage tissues [3]. Traditionally, the process of stem cell differentiation has been controlled using media containing specific regulator proteins and biomolecules (e.g., dexamethasone, ascorbic acid, and $\beta$-glycerophosphate) [4]. However, since cells actively interact with the underlying substrates/surfaces wherein they attach and grow, a 
method for controlling their functions including proliferation, migration, and differentiation, via biophysical factors, instead of induction media or the combination of two, has been recently proposed [5-7]. Such biophysical stimuli are induced by modifying the substrate/surface with cell-matrix interactions, which ultimately influence both cytoskeletal mechanics and cellular gene/ protein expression $[8,9]$.

Until now, a variety of nanomaterials, including carbon nanotube (CNT) [10], fullerenes, and graphene [11], have been reported to guide stem cell differentiation with or without the presence of soluble differentiation factors. Among such materials, graphene and its derivative, graphene oxide (GO), have gained attention as unique materials to induce the physical stimulation required for stem cell differentiation. It has been reported that these features of amphiphilicity, surface chemistry, and honeycomb structures of GO $[12,13]$ affect cytoskeletal dynamics of cells adhered to the GO surface, which ultimately result in the changes of cell spreading, morphology and proliferation [14-16].

Several studies have reported the application of twodimensional materials including graphene and its derivatives for productive differentiation of stem cells into desired lineages. Particularly, graphene oxide micropatterns, graphene nanopatterns, graphene, and nanomaterials hybrid platforms have been reported to promote the differentiation of hMSCs into osteocytes, adipocytes, and chondrocytes [17-22]. This is also attributed to unique surface properties such as absorption/repulsion of specific differentiation factors, and the enhancement of cell adhesion through interactions between the cell membrane and the surface of the carbon materials [23, 24].
On the other hand, other nanomaterials have been tested for drug delivery and other stem cell therapeutic applications [25-27]. Their particle size, large surface area, and an ability to translocate into cells have shown promising prospects in noble biomedical utilizations [28-30]. Gold nanoparticles (AuNPs), a representative material in biomedical research, are best known for relatively low cytotoxicity, biocompatibility, and versatility on surface modification [31-33]. Moreover, efforts have been made to apply three-dimensional structures to cell culture experiments [34-36]. Henceforth, this study focuses on the following three categories: (i) controlling the hMSCs using carbon-based materials, (ii) differentiation of hMSCs through nanomaterials, and (iii) effects of bionano platform on cell behaviors. We have narrowed our focus to bionano hybrid platform to two-dimensional materials, AuNPs, RGD peptide (arginyl-glycyl-aspartic acid), and silica nanoparticles, all of which are known to be good for cell adhesion. (Fig. 1).

\section{Main text \\ Mesenchymal stem cells behaviors on two-dimensional materials}

hMSCs have been shown as a promising source for stem cell therapies and regenerative medicine due to their ability to self-renew and differentiate toward various types of cells, such as osteocytes, adipocytes, and chondrocytes [37-40]. In addition, they can be easily isolated from the bone marrow, fat, and umbilical cord, and successfully expanded in vitro [41, 42]. However, several carbon-based materials have been lauded as versatile tools for establishing the future generation of biomaterials [43-45]. Although each carbon-based material,

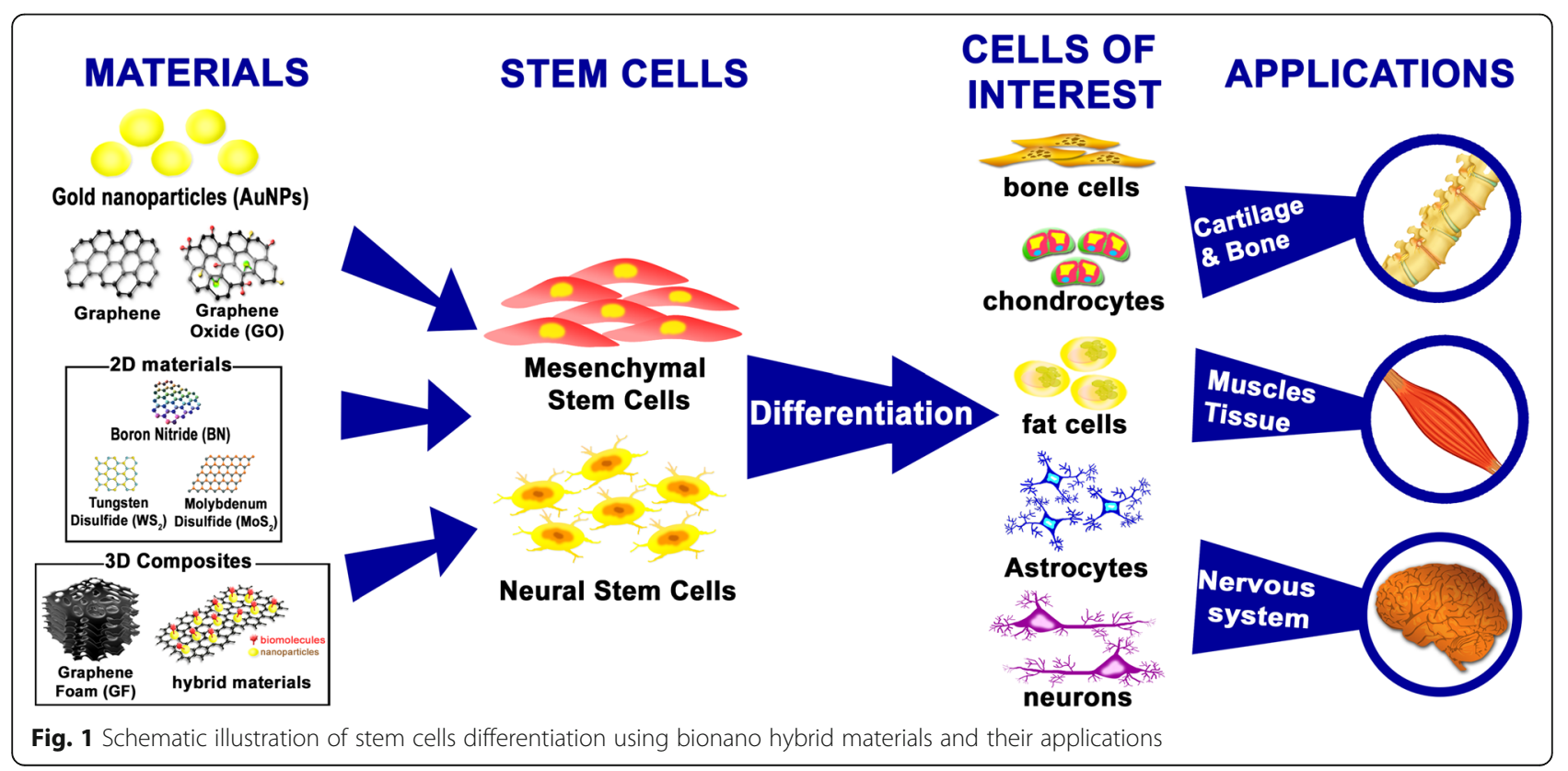


such as fullerene, carbon nanotubes, and graphene, presents its own advantages and disadvantages, graphene and its derivatives in particular have been used to guide the behavior of hMSCs [21, 46-48]. Graphene has several features that are advantageous for biomedical applications, owing to unique physiochemical properties, from its surface chemistry, amphiphilicity, and specific carbon structures [49]. Subsequently, graphene and GO, once fully exploited, would drastically influence the spreading, morphology, and proliferation of stem cells, and become prospects for osteogenic differentiation of hMSCs [50, 51].

Generally, carbon-based materials are prepared by chemical vapor deposition (CVD), which ensures high quality and high volume production, before being transferred to a variety of substrates [24, 52]. For instance, graphene is usually functionalized in order to enhance the bioactivity of hybrid composite before being used as a surface coating on biomaterial substrates [53]. Many researches have reported that graphene has the ability to guide osteogenic differentiation of hMSCs. For example, Nayak et al. found that graphene induces osteogenic differentiation when cultured without BMP-2, a common growth factor in bone formation [11] (Fig. 2). The stark difference in alizarin red s (ARS) data between Fig. 2b and $c$ show that calcification in graphene is higher even in the absence of BMP-2, and Fig. 2e-h show that osteogenesis differs depending on the presence or absence of graphene and BMP-2.
On the other hand, Lee et al. [4] discovered that the binding ability of graphene with several osteogenic differentiation factors could enhance the differentiation of hMSCs into the osteogenic lineage. They conducted an experiment wherein they cultured hMSCs on the CVD graphene. Several osteogenic differentiation factors, such as dexamethasone, ascorbic acid, and $\beta$-glycerophosphate, were used in the culturing process. The result showed that graphene had the ability to promote osteogenesis of hMSCs within 12 days, which was 9 days shorter than the prior studies. It indicates that osteogenesis in the presence of graphene could be achieved earlier than with conventional substrates.

In addition, Suhito et al. compared the osteogenic differentiation of hMSCs on graphene oxide and other graphene-like 2D materials such as molybdenum sulfide $\left(\mathrm{MoS}_{2}\right)$, tungsten sulfide $\left(\mathrm{WS}_{2}\right)$, and boron nitride $(\mathrm{BN})$ [54]. Figure 3 visualizes osteogenic and adipogenic differentiation in hMSCs using the 2D materials mentioned above. As shown in Fig. 3 (a), (c), and (d), the osteogenic differentiation was confirmed on each substrate, and most of the hMSCs grown on each substrate were fully differentiated. However, the results from optical microscopy, ARS, and qPCR showed that the best differentiation rate was obtained at the GO concentration of $50 \mu \mathrm{g} / \mathrm{mL}$.

Figure 3 (b) and (e), represent the oil red $\mathrm{O}(\mathrm{ORO})$ staining, which stains lipids when hMSCs are differentiated into adipocytes, demonstrating the adipogenetic capacity of hMSCs. Upon quantification, it was confirmed
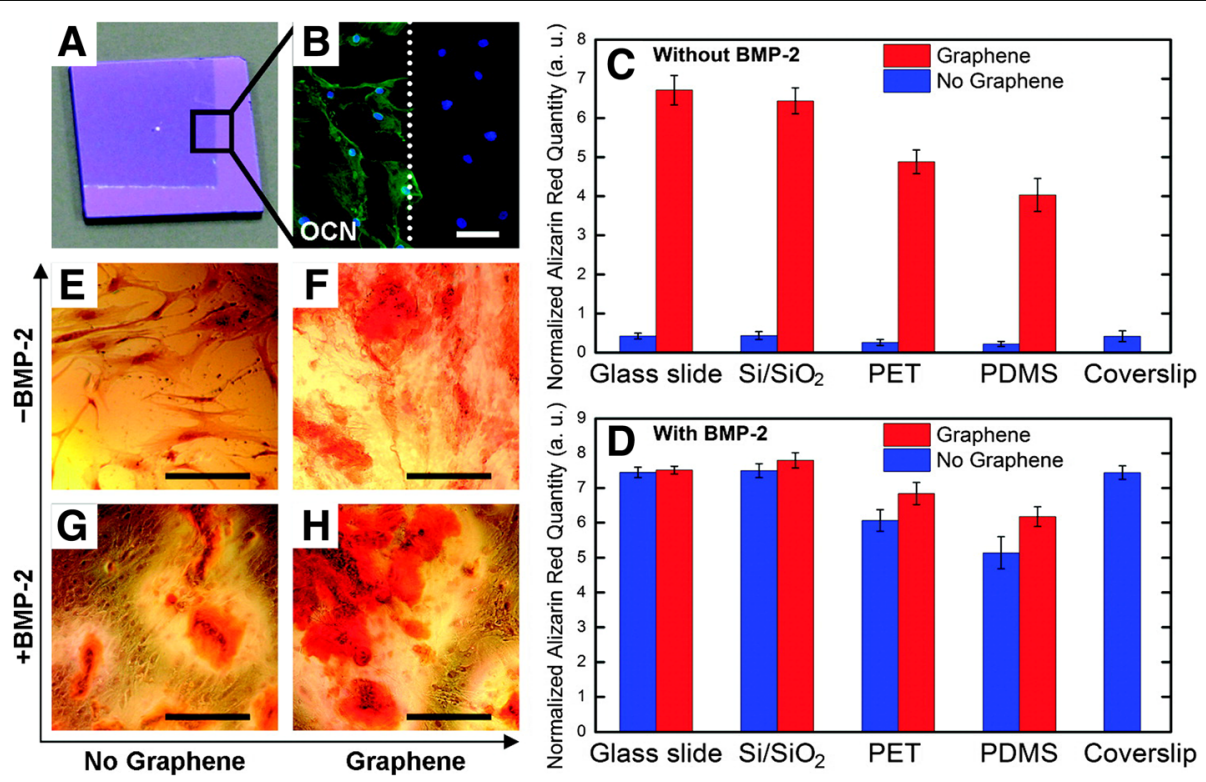

Fig. 2 Enhancement of osteogenic differentiation on graphene substrates with/without BMP-2. (a) Optical image of graphene-coated $\mathrm{Si}_{/} \mathrm{SiO}_{2}$ substrate. The boundary is shown for the graphene-coated part. (b) Osteocalcin $(\mathrm{OCN})$ staining, a marker of osteogenic differentiation. Green $=\mathrm{OCN}$, Blue = DAPI. (c, d) Alizarin Red S (ARS) quantification graphs during 15 days on substrates with/without graphene. (e-h) polyethylene terephthalate (PET) substrate stained with ARS, showing calcium deposits due to osteogenic differentiation. Reprinted with permission from [11]. Copyright (2011) American Chemical Society 

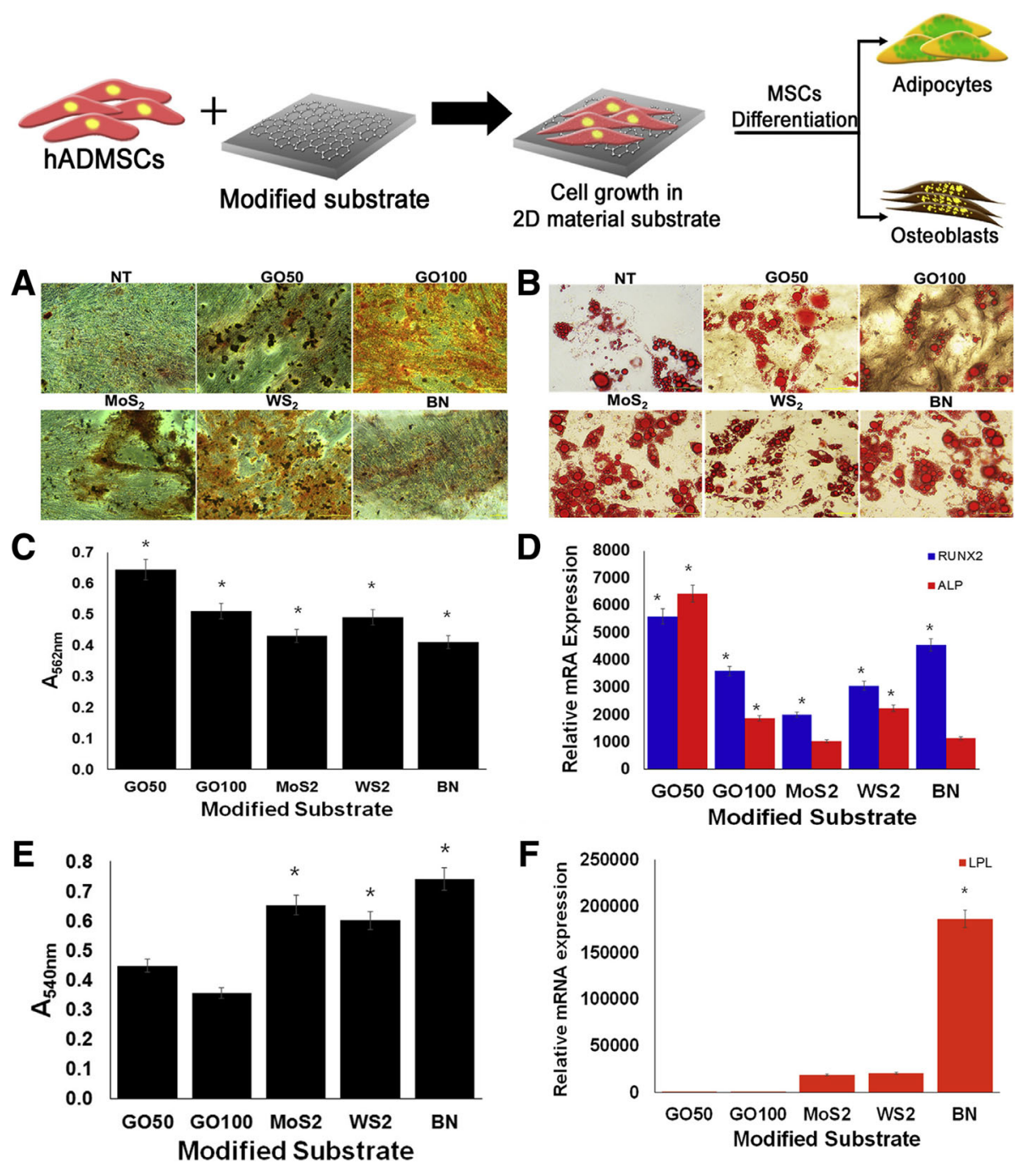

Fig. 3 The various differentiation indicators in accordance with their respective 2D materials substrates. (a) Optical images of osteogenesis confirmed by ARS. (b) Oil Red O (ORO) staining images of each substrates. (c) Quantification graph of ARS result, and (d) gene expression level of osteogenic markers by qPCR. (e) ORO results converted to a quantified graph. (f) qPCR analysis data on adipogenic marker gene of expression level. (* $p<0.05)$ (GO: graphene oxide, MoS2: molybdenum sulfide, WS2: tungsten sulfide, BN: boron nitride) Copyright 2017, Royal Society of Chemistry

that the rate of adipogenesis in other substances was much higher than that in GO. Moreover, Fig. 3 (f) shows that the gene expression level of the hMSCs grown on BN substrates was the highest among the test substrates.

In addition, it is also known that graphene oxide nanoribbon (GONR) and reduced graphene oxide nanoribbon (rGONR) grids influence the osteogenic differentiation and proliferation of hMSCs, regardless of the presence or absence of differentiation inducing factors [18].

When osteogenic factors were present, the fastest osteogenic differentiation of hMSCs in rGONR grids was found to occur in about 7 days. The rapid osteogenic differentiation in rGONR was thought to be due to the high adsorption of differentiation inducing substances by rGONR and the physical properties induced by the surface characteristics of the nanogrids.

Moreover, many studies have confirmed the effects of graphene on the differentiation of other stem cells as well as hMSCs. For example, Chen et al. [55] reported the biocompatibility of $\mathrm{G}$ and $\mathrm{GO}$ toward long-term culture of induced pluripotent stem cells (iPSCs). Interestingly, iPSCs cultured on $\mathrm{G}$ and $\mathrm{GO}$ showed imbalance in differentiation tendencies. Especially, in the endodermal lineages, $G$ interrupted spontaneous differentiation. On the other hand, GO promotes the differentiation of iPSCs most prominently along the ectodermal pathway, but differentiation into ectoderm and mesodermal is similar to iPSC incubated in both G and GO. 
Consequently, it was found that graphene, GO, and other two-dimensional materials with their unique chemical and physical characteristics, enhance and guide the osteogenic or adipogenic differentiation of hADMSCs. In addition, we could confirm that 2D materials have various effects on the differentiation of hMSCs as well as other types of stem cells. This demonstrated that carbon-based materials were potential materials not only for regenerative medicine but also for the biomedical fields.

\section{The effect of gold nanoparticles (AuNPs) on hMSCs growth and differentiation}

Another type of nanomaterial with broad potential in biomedical application is gold nanoparticles (AuNPs). As mentioned already, AuNPs have been proposed as an attractive material for regenerative medicine, owing to their favorable physical properties, including biocompatibility arising from their low cytotoxicity, and abundant control over the particle size [56-58]. Numerous studies have investigated their application in biomedical fields such as biological imaging, chemical sensing, drug carriers, and disease treatments [59-63]. Most importantly, the negative charge on the surface of AuNPs makes gold nanoparticles more easily modifiable than the other NPs, such that the AuNPs can be functionalized by a wide range of biomolecules, drugs, DNA, antibodies, and functional peptides/polymers for favorable biomedical research and therapy [64].

Previously, AuNPs, functionalized with polymers such as chitosan-conjugated AuNPs, were developed to achieve advanced differentiation of human mesenchymal Stem Cells (hMSCs) [65]. Chitosan, a type of aminated polysaccharide that has been utilized in bone tissue engineering, shows similarity to glycosaminoglycan, which plays an important role in extracellular matrix (ECM) interaction during cell adhesion. Moreover, further investigation discovered that chitosan polymers can promote osteogenic differentiation through $\mathrm{Wnt} / \beta$-catenin signaling pathway $[66,67]$. However, AuNPs themselves have been found to promote osteogenic differentiation of hMSCs by their stimulation through protein kinase 38 (p38) mitogen-activated protein kinase (MAPK) pathway. The difference in charge and the moiety of AuNPs have been shown to induce a series of cell responses towards osteogenesis [33]. Hence, Yi et al. studied the use of AuNPs as a novel biomaterial to enhance the osteogenic differentiation of hMSCs and the associated molecular mechanisms [33].

Figure 4 illustrates the role of AuNPs in terms of gene regulation through osteogenesis of hMSCs. The AuNPs would attach to the hMSC membrane and bind to proteins in the cytoplasm. This is followed by internalization via endocytosis, which induces mechanical stress in the cell. It has been revealed that several signaling molecules play an important role in signal transduction. A hypothesis stated that AuNPs may serve as mechanical stimulator for hMSCs in terms of the activation of MAPK signaling pathway in the cells, thus, inducing their preferential differentiation. The stimulation of p38 MAPK signaling mechanism leads to an up-regulation of transcription factors that are related to osteogenic differentiation, such as RUNX2. It then subsequently triggers several marker genes for osteogenesis, such as $\mathrm{Col}$ I and BMP-2 at the early stages, and ALP and OCN at the later stages of differentiation. According to other type of hMSC differentiation such as adipogenesis, the activation of p38 MAPK pathway delivers to the downregulation of adipogenic marker genes, e.g., PPAR $\gamma$ and $\mathrm{C} / \mathrm{EBP} \alpha[68,69]$. Therefore, AuNPs could inhibit the adipogenic differentiation of hMSCs.

Based on the results shown in Fig. 5a, the assessment of ALP activity from hMSCs cultured on 7, 10, and 14 days effectively demonstrates the effect of AuNPs toward osteogenesis. These data represent the increase in ALP activity due to stronger promotion of osteogenic differentiation of hMSCs followed by the increase in AuNP concentration, especially on day 14. In addition, ARS staining assay was performed to account for the mineralization in osteoblasts. In Fig. 5b, the AuNPs showed similar promotive effects on mineral formation in hMSCs. The ARS quantitative data referring to the mineralized-nodules in osteoblasts upon AuNPs treatment was significantly increased in a dose- and timedependent manner. At day 21, the mineralization in the presence of $1 \mathrm{nM}$ AuNPs was 45\% higher than those of other groups (see Fig. 5b) [33].

Therefore, it can be concluded that AuNP surface functionalization with biomolecules is an effective strategy to enhance stem cell growth and differentiation. Although the use of AuNPs is highly promising in the field of stem cells for regenerative and therapy, further studies are needed to examine and develop the compatibility of various molecules in terms of nanoparticles conjugation for biological research.

\section{Controlling differentiation of hMSCs using modified 3D graphene-based platform}

In terms of controlling the differentiation of hMSCs, various attempts have been made using a modified platform. Especially, a platform that modified threedimensional (3D) graphene-based substrates has been currently in spotlight due to its similarity with the 3D microenvironment ECM in human body [70-75]. It has been shown that the transport behaviors of cytokines, chemokines, and growth factors are significantly different in 2D and 3D microenvironments, which would consequently influence signaling transduction, cell-cell communications, and tissue development $[9,76-80]$. To 


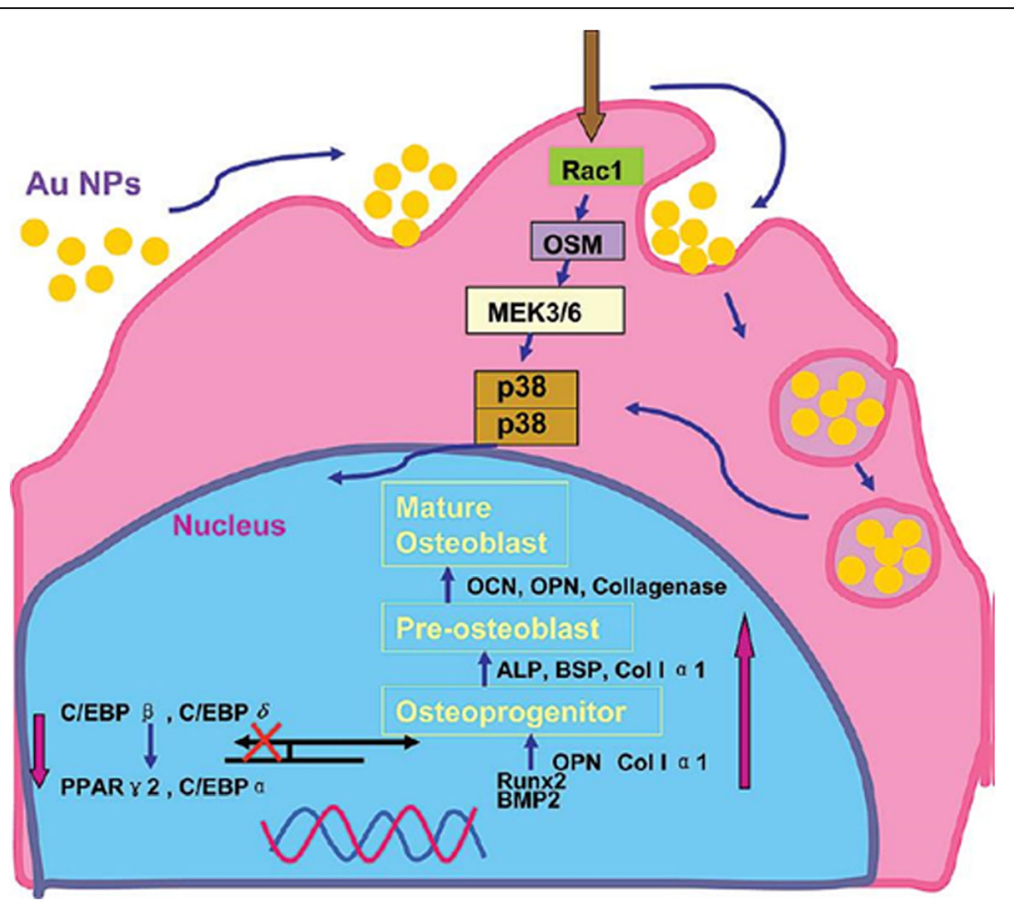

Fig. 4 Illustration showing molecular mechanism of the modulation of osteogenic differentiation of hMSCs by AuNPs through p38 MAPK signaling pathway. Reprinted with permission from [29]. Copyright 2017 American Chemical Society

address these issues, we highlighted the various developments that have been made to differentiate the hMSCs with graphene-based 3D platform in relation to notable properties of graphene mentioned above (see Table 1). First of all, 3D graphene foams (GFs) were utilized as an hMSCs cultivation substrate [81]. It is known that 2D graphene sheets can accelerate the differentiation of hMSCs in presence of osteogenesis induction media $[11,24]$. Crowder et al. hypothesized that a 3D GF would accelerate differentiation of hMSCs more effectively than a 2D graphene sheet. Based on previous studies, 3D GFs have been utilized for multifarious applications such as battery technology and electrochemical sensing [82, 83]. However, the authors investigated that 3D GFs are capable of being used as novel culture substrates for cell growth and inducing spontaneous osteogenic differentiation of hMSCs. Figure 6a-c show SEM images of hMSCs cultured on GFs for 4 days. Interestingly, the protrusion of the cells spread across large pores in the GF and interact with the GF surface. We discovered that the 3D GFs were highly
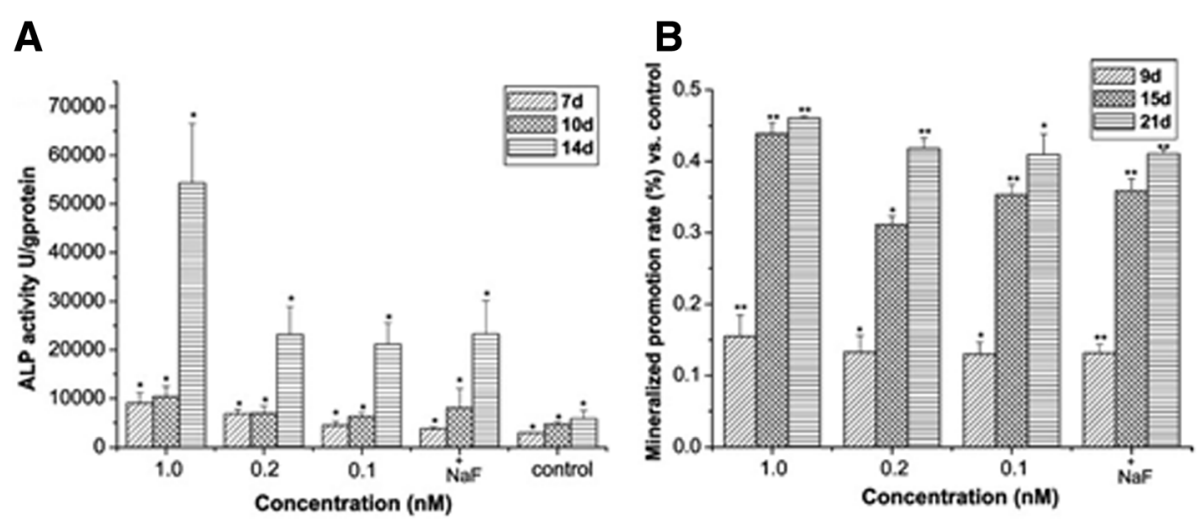

Fig. 5 The effects of gold nanoparticles (AuNPs) on osteogenesis of human mesenchymal stem cells (hMSCs). (a) Effects of AuNPs on the ALP activity of hMSCs. Results are mean \pm SD of triplicate experiments: $\left(^{*}\right) p<0.01$. (b) Effects of AuNPs on the mineralized nodule formation of hMSCs. Mineralization quantitated by elution of Alizarin Red S from stained mineral deposits. Results are mean \pm SD of triplicate experiments: $\left(^{*}\right) p<0.05$, $\left(^{* *}\right) p<0.01$. NaF at $1 \mu \mathrm{M}$ used as a positive control for both experimental data. Reprinted with permission from [29]. Copyright 2017 American Chemical Society 
Table 1 Summary of studies using 3D graphene-based substrate for differentiation of MSCs

\begin{tabular}{|c|c|c|c|c|}
\hline 3D platform & Type of carbon-based material & Type of cells & Outcomes & Reference \\
\hline GFs & Graphene foam & hBMMSCs & $\begin{array}{l}\text { GFs promoted osteogenic differentiation without } \\
\text { the use of chemical inducers. }\end{array}$ & {$[81]$} \\
\hline $\begin{array}{l}\text { rGO-Collagen } \\
\text { hybrid (PADM-rGO) }\end{array}$ & Reduced Graphene Oxide & rBMMSCs & $\begin{array}{l}\text { PADM-rGO promoted the differentiation of MSCs } \\
\text { into neural cells after } 7 \text { days under neural } \\
\text { differentiation condition. }\end{array}$ & [102] \\
\hline GC & Graphene & hBMMSCs & $\begin{array}{l}\text { The graphene / calcium silicate (GC) composite } \\
\text { coating promoted adhesion and osteogenic } \\
\text { differentiation of hMSCs and greatly increased the } \\
\text { expression of genes involved in differentiation }\end{array}$ & [94] \\
\hline HAp & Reduced Graphene Oxide & hMSCs & $\begin{array}{l}\text { rGO - coated HA not only significantly enhanced } \\
\text { osteogenic differentiation capacity of hMSC in } \\
\text { osteogenic medium, but also significantly increased } \\
\text { differentiation ability in basal medium. }\end{array}$ & {$[51]$} \\
\hline GO-PEDOT & Reduced Graphene Oxide & hBMMSCs & $\begin{array}{l}\text { GO-PEDOT controlled osteogenic differentiation } \\
\text { of hMSCs through electrical stimulation. }\end{array}$ & [99] \\
\hline
\end{tabular}

hBMMSC human bone-marrow mesenchymal stem cell, GF graphene foam, GC graphene/calcium silicate, HAp hydroxlyapatite, PEDOT poly (3, 4-ethylenedioxyphene)

porous, with individual pore sizes exceeding $100 \mathrm{~mm}$, and that the hMSCs had sensed and spanned across the pores. In Fig. 6d, hMSCs morphology seems significantly different on GFs compared with the tissue culture polystyrene (TCPS). As the GFs have a highly porous 3D structure, as shown in Fig. 6e, the attachment of hMSCs cultured in GF was observed to be much lower than that on TCPS. However, the cells were spontaneously stimulated into osteogenic differentiation (Fig. 6f), even though the cell culture media did not contain osteogenetic inducers. In addition, due to the physical properties of GFs, such as flexibility and conductivity $[84,85]$, GFs have been studied for effective proliferation and differentiation of human neural stem cells (hNSCs) in the presence of electrical stimulation [86]. Akhavan et al. discovered that hNSCs, grown on the GF with electrical stimulation, resulted in a much higher rate of proliferation and accelerated differentiation into neurons.

Guo et al. suggested a novel 3D scaffold for neural differentiation of hMSCs. They used a 3D porcine acellular
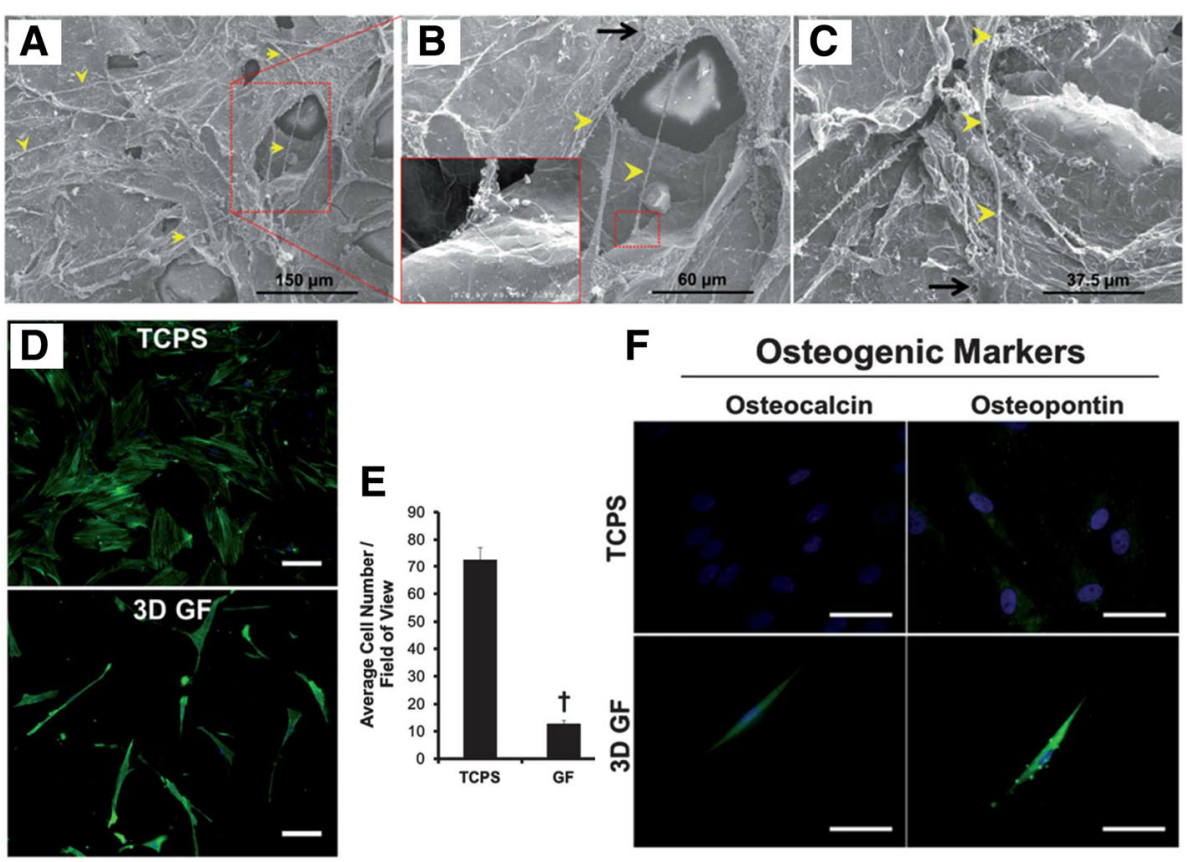

Fig. 6 The effects of 3D graphene foams (GFs) on the adhesion and osteogenic differentiation of human mesenchymal stem cells (hMSCs). (a - c) The SEM images of hMSCS cultured on 3D GFs for 4 days. The yellow arrows represent formed protrusions up to $100 \mathrm{~mm}$ in length that extended from small cell bodies (black arrows). (d) Immunofluorescence images of hMSCs cultured on TCPS and 3D GFs for 7 days. (e) The average cell number was quantified from Fig. 6d. (f) Immunofluorescence images stained with osteogenic markers, Osteocalcin and Osteopontin, for hMSCs cultured on TCPS and GF for 7 days. Scale bar $=50 \mu \mathrm{m}$. Copyright @ 2013, Royal Society of Chemistry 
dermal matrix (PADM), mostly comprised of collagen I as a base scaffold, and assembled a layer of reduced graphene oxide (rGO). The fabricated PADM-rGO demonstrated an effective electrical conductivity and a typical porous structure (pores ranging from 50 to $150 \mu \mathrm{m}$ in size). The hMSCs were then cultured on PADM and PADM-rGO for $24 \mathrm{~h}$ and underwent live/dead cellular staining. The cells maintained the archetypal spindle shape of hMSCs as seen in Fig. 7A a-f [9, 87, 88]. After 3 days of cultivation on each scaffold, the immunofluorescence images indicated that the density of cells on PADM-rGO was slightly higher than that of the cells on PADM (Fig. 7A g-i). As shown in Fig. 7B, the neural specific gene expression of cultured hMSCs for 7 days demonstrated that PADM-rGO accelerated the differentiation of hMSCs into neural cells.

Among numerous candidates, it has been previously studied that composite coating with $\mathrm{HA} / \mathrm{CNTs}$ presented higher durability and longer maintenance period than the conventional HA coating [89-91]. In this regard, graphene has received substantial attention, which is composed of the same material as CNTs [92], but has a higher surface area, thermal conductivity, and flexibility. It is also well known for its high biocompatibility and harmlessness, which is considered to be important for grafting [93]. In this regards, Xie et al. studied graphene-reinforced calcium silicate coating $(\mathrm{GC})$ technique, which was found be effective to generate a hierarchical nano-/microstructured surface [94]. The hMSCs were cultured on the GC. As a result, the wear resistance was increased compared with the conventional CS coating, and the adhesion and proliferation of hMSCs in vitro were enhanced when the GC coating was applied. In addition, it was confirmed that gene expression related to osteogenesis, alkaline phosphatase (ALP), osteocalcin (OC), and osteopontin (OPN), was increased. In addition,
A
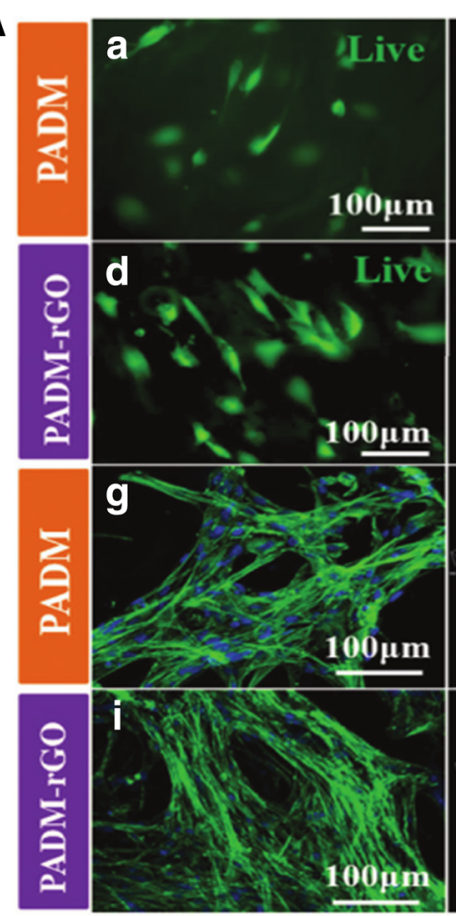

B

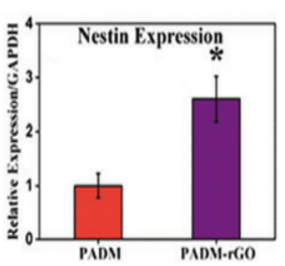

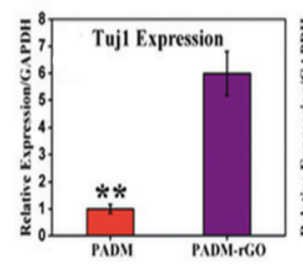
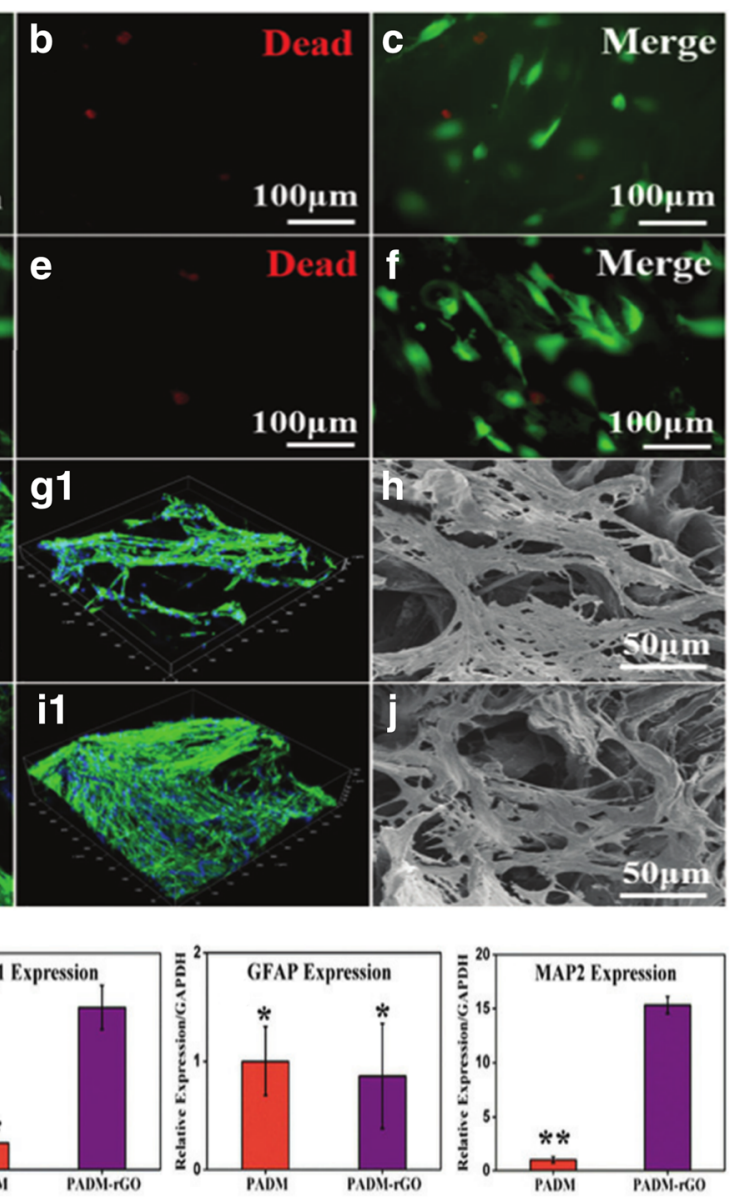

Fig. 7 The effects of 3D porcine acellular dermal matrix (PADM) and PADM-reduced graphene oxide (PADM-rGO) on the adhesion and neuronal differentiation of human mesenchymal stem cells (hMSCs). (a) The cytocompatibilities of the two different scaffolds. The hMSCs were cultured on the PADM $(a, b, c)$ and PADM-rGO (d, e, f) for 24 h, Live/dead staining was performed. The live cells are stained green, and dead cells are red. CLSM fluorescence morphologies of the actin cytoskeleton of the hMSCs cultured on the PADM (g) and PADM-rGO (i) scaffolds for 3 days. (h - j) SEM images represent the cell attachment of hMSCs after 3 days on the PADM and PADM-rGO. (b) Quantification of qPCR analysis for neural marker genes; Nestin, Tuj1, GFAP, and MAP2, expression of hMSCs. Copyright @ 2015, Royal Society of Chemistry 
rGO exhibits exceptional properties, similar to properties of graphene, as mentioned above. In addition, it has been recently shown by many researchers that graphene has the potential to guide osteogenesis of hMSCs $[4,11]$. Hydroxylapatite (HA), in the form of microparticles, forms a three-dimensional environment to enhance cell adhesion and proliferation [95]. By employing the advantages of these two materials, the authors developed rGO coated HA. Moreover, they demonstrated the enhancement of osteogenic differentiation of hMSCs when incubated in basal medium without any osteo-inductive molecules [51]. In addition, the osteogenic activity of cells was further improved in osteogenic medium. The researchers assumed that the initial exposure of rGO-coated HA to cells facilitated intracellular signaling via a more intricate pathway. However, further research is required to explore the actual mechanism.

While scientists have traditionally relied on physical or chemical methods to examine biological entities, certain biological information (gene expression, differentiation, proliferation) can be obtained and monitored using electrical stimulation [96-98]. Hsiao et al. designed a novel $3 \mathrm{D}$ cell culture electrode with multifunctional graphene-

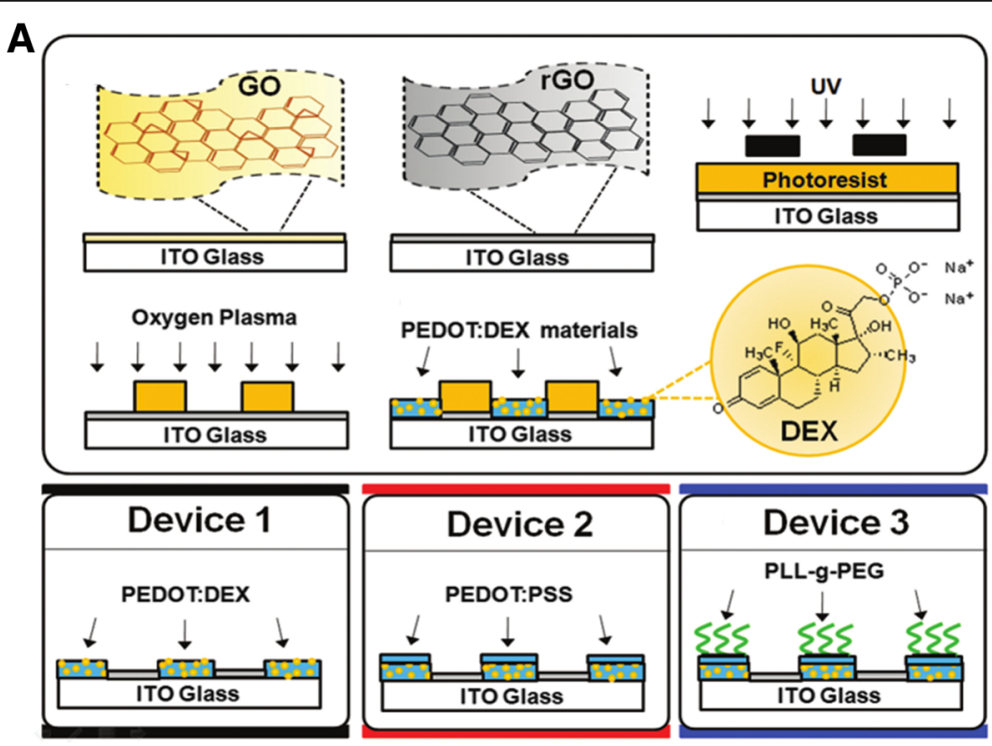

B
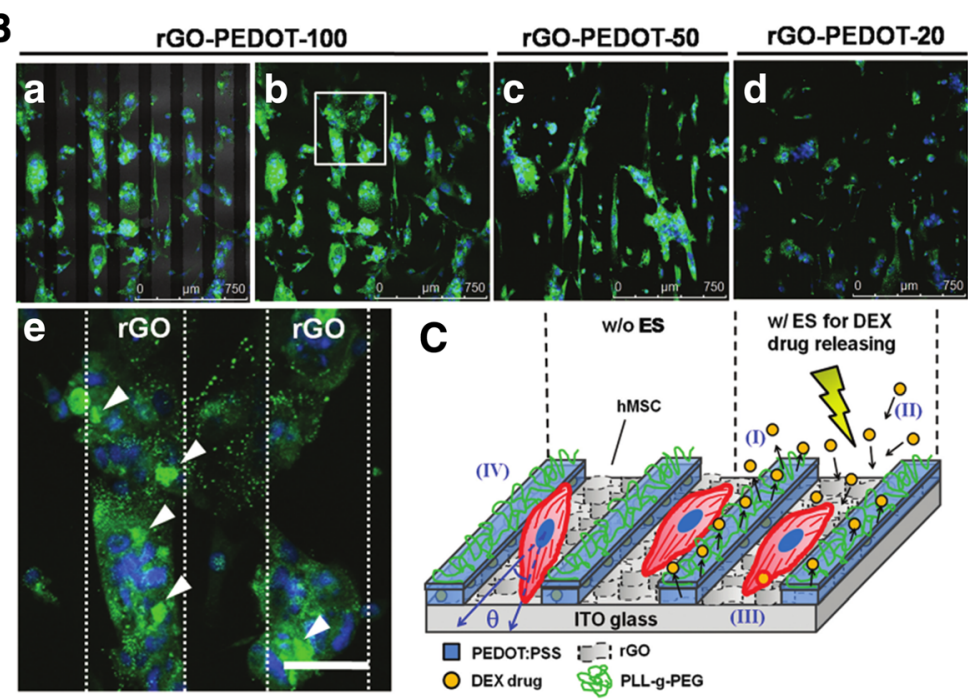

Fig. 8 The osteogenic differentiation of human mesenchymal stem cells (hMSCs) induced by electrical release of differentiation factor, dexamethasone (DEX). (a) Schematic diagram represents the fabrication process of DEX-loaded bioelectrode array. (b) Immunofluorescence images of OCN expression in hMSCs cultured on various sizes of rGO-PEDOT (rGO-PEDOT-20, rGO-PEDOT-50, and rGO-PEDOT-100). (c) Schematic representation for rGO-PEDOT behavior. Copyright $\odot 2013$ WILEY-VCH Verlag GmbH \& Co. kGaA, Weinheim 
PEDOT microelectrode and successfully controlled the osteogenic differentiation of hBMMSCs through electrical stimulation [99]. Materials used in this platform were electrically conductive indium tin oxide (ITO) glass and poly (3, 4-ethylenedioxyphene) (PEDOT) [100]. In addition, they used reduced graphene oxide (rGO), which is known to promote differentiation of hMSCs, to promote cell adhesion [95]. As a result, the researchers created the platform illustrated in Fig. 8a. The PEDOT pattern containing dexamethasone 21-phosphate disodium (DEX), which is one of differentiation inducers required for hMSC osteogenesis, and the hMSC aligned between them are cultured under the influence of the rGO. Subsequently, the PEDOT released the DEX only when an electric stimulation was provided (Fig. 8b). Therefore, Hsiao's platform is shown to easily control the differentiation of hMSCs using only the electrical stimulation.

Conclusively, we have highlighted several 3D graphenebased platforms as a substrate for differentiation of hMSCs in this Review. The biocompatibility of these modified 3D scaffolds could be widely utilized for tissue engineering applications such as bone regeneration therapy.

\section{Conclusion}

In this review, we focused on several studies that used various nanohybrid materials for biomedical applications, with a particular focus on the use of two-dimensional materials, gold nanoparticles, and three-dimensional graphene composites [101].

Some of the prior reports have confirmed that twodimensional materials and nanomaterials in combination with biological materials (e.g., growth factors, peptide, and proteins) enhance a number of cellular behaviors including cell adhesion, proliferation, migration and differentiation. Interestingly, these materials were especially excellent in performing as an attracting signal, not just for the osteogenesis of hMSCs but also for the enhancement of bone regeneration process.

In addition, three-dimensional carbon nanomaterials also have been utilized as the platform to support stem cell growth and differentiation. Unlike the twodimensional platforms, which turned out to be suitable for controlling stem cells functions/behaviors in vitro, the three-dimensional carbon nanomaterials were found to be excellent in constructing $3 \mathrm{D}$ in vivo-like conditions ex vivo. Such approaches were useful to mimic structures of human tissues/organs, which is critical for the development of a new types of in vitro drug-screening tool such as organ-on-a-chip, as well as to develop tissue-biomaterial composites for the transplantation purpose. Although the use of bionano platforms for tissue regeneration is still in its early stages of development, certain biochemical and physical properties of those platforms, which includes tunable physical sizes, shapes, surface hydrophilicity, functional groups, entail a promising future for its development in biomedical fields, especially for the stem cell-based regenerative therapies.

\section{Abbreviations \\ ARS: Alizarin red S; AuNPs: Gold nanoparticles; CNT: Carbon nanotube; CS: Calcium silicate; CVD: Chemical vapor deposition; ECM: Extracellular matrix; \\ GO: Graphene oxide; HA: Hydroxylapatite; hMSCs: Human mesenchymal stem cell}

\section{Acknowledgements}

Not applicable.

\section{Funding}

This research was supported by a grant from the Korea Health Technology R\&D Project through the Korea Health Industry Development Institute (KHIDI), funded by the Ministry of Health \& Welfare (grant number: HI15C3051); by a grant from the National Research Foundation of Korea (NRF) (grant number: 2016R1C1B1016088); and by the Nano Material Technology Development Program through the National Research Foundation of Korea (NRF) funded by the Korea Government (MSIP) (NRF-2014M3A7B4051907).

\section{Availability of data and materials}

Not applicable.

\section{Author's contributions}

ESK, DSK, IRS, WHL and IS searched references and collected information. THK established the structure of whole manuscript. ESK, DSK, IRS, WHL, IS and THK managed the figures and figure captions. All authors wrote and reviewed the manuscript. All authors read and approved the final manuscript.

Ethics approval and consent to participate

Not applicable.

\section{Consent for publication}

Not applicable.

\section{Competing interests}

The authors declare that they have no competing interests.

\section{Publisher's Note}

Springer Nature remains neutral with regard to jurisdictional claims in published maps and institutional affiliations.

Received: 28 December 2017 Accepted: 9 March 2018 Published online: 02 April 2018

\section{References}

1. Kim YJ, Hwang SJ, Bae YC, Jung JS. MiR-21 regulates Adipogenic differentiation through the modulation of TGF- $\beta$ signaling in mesenchymal stem cells derived from human adipose tissue. Stem Cells. 2009:27:3093-102.

2. zur Nieden NI, Kempka G, Rancourt DE, Ahr HJ. Induction of chondro-, osteoand adipogenesis in embryonic stem cells by bone morphogenetic protein-2: effect of cofactors on differentiating lineages. BMC Dev Biol. 2005;5:1.

3. Derfoul A, Perkins GL, Hall DJ, Tuan RS. Glucocorticoids promote Chondrogenic differentiation of adult human mesenchymal stem cells by enhancing expression of cartilage extracellular matrix genes. Stem Cells. 2006;24:1487-95.

4. Lee WC, Lim CHYX, Shi H, Tang LAL, Wang Y, Lim CT, Loh KP. Origin of enhanced stem cell growth and differentiation on graphene and graphene oxide. ACS Nano. 2011:5:7334-41.

5. Christopherson GT, Song H, Mao H-Q. The influence of fiber diameter of electrospun substrates on neural stem cell differentiation and proliferation. Biomaterials. 2009;30:556-64.

6. Discher DE, Mooney DJ, Zandstra PW. Growth factors, matrices, and forces combine and control stem cells. Science. 2009;324:1673. 
7. Du J, Chen X, Liang X, Zhang G, Xu J, He L, Zhan Q, Feng X-Q, Chien S, Yang $C$. Integrin activation and internalization on soft ECM as a mechanism of induction of stem cell differentiation by ECM elasticity. Proc Natl Acad Sci. 2011;108:9466.

8. Engler A, Sweeney H, Discher D, Schwarzbauer J. Extracellular matrix elasticity directs stem cell differentiation. J Musculoskelet Neuronal Interact. 2007;7:335.

9. Engler AJ, Sen S, Sweeney HL, Discher DE. Matrix elasticity directs stem cell lineage specification. Cell. 2006;126:677-89.

10. Mooney E, Dockery P, Greiser U, Murphy M, Barron V. Carbon nanotubes and mesenchymal stem cells: biocompatibility, proliferation and differentiation. Nano Lett. 2008;8:2137-43.

11. Nayak TR, Andersen H, Makam VS, Khaw C, Bae S, Xu X, Ee P-LR, Ahn J-H, Hong BH, Pastorin G, Özyilmaz B. Graphene for controlled and accelerated osteogenic differentiation of human mesenchymal stem cells. ACS Nano. 2011:5:4670-8

12. Allen MJ, Tung VC, Kaner RB. Honeycomb carbon: a review of graphene Chem Rev. 2010;110:132-45.

13. Geim AK, Novoselov KS. The rise of graphene. Nat Mater. 2007;6:183.

14. Chang Y, Yang S-T, Liu J-H, Dong E, Wang Y, Cao A, Liu Y, Wang H. In vitro toxicity evaluation of graphene oxide on A549 cells. Toxicol Lett. 2011;200:201-10.

15. Jeon J, Lee MS, Yang HS. Differentiated osteoblasts derived decellularized extracellular matrix to promote osteogenic differentiation. Biomater Res. 2018;22:4.

16. Wang Y, Lee WC, Manga KK, Ang PK, Lu J, Liu YP, Lim CT, Loh KP. Fluorinated graphene for promoting neuro-induction of stem cells. Adv Mater. 2012;24: 4285-90.

17. Akhavan O, Ghaderi E. Differentiation of human neural stem cells into neural networks on graphene nanogrids. J Mat Chem B. 2013;1:6291.

18. Akhavan O, Ghaderi E, Shahsavar M. Graphene nanogrids for selective and fast osteogenic differentiation of human mesenchymal stem cells. Carbon. 2013;59:200-11

19. Kim J, Kim HD, Park J, Lee ES, Kim E, Lee SS, Yang JK, Lee YS, Hwang NS. Enhanced osteogenic commitment of murine mesenchymal stem cells on graphene oxide substrate. Biomater Res. 2018;22:1.

20. Kim T-H, Shah S, Yang L, Yin PT, Hossain MK, Conley B, Choi J-W, Lee K-B. Controlling differentiation of adipose-derived stem cells using combinatorial graphene hybrid-pattern arrays. ACS Nano. 2015;9:3780-90.

21. Shah S, Yin PT, Uehara TM, Chueng S-TD, Yang L, Lee K-B. Guiding stem cell differentiation into oligodendrocytes using graphene-nanofiber hybrid scaffolds. Adv Mater. 2014;26:3673-80.

22. Solanki A, Shah S, Memoli KA, Park SY, Hong S, Lee K-B. Controlling differentiation of neural stem cells using extracellular matrix protein patterns. Small. 2010;6:2509-13.

23. Cha C, Shin SR, Annabi N, Dokmeci MR, Khademhosseini A. Carbon-based nanomaterials: multifunctional materials for biomedical engineering. ACS Nano. 2013;7:2891-7.

24. Dubey N, Bentini R, Islam I, Cao T, Castro Neto AH, Rosa V. Graphene: a versatile carbon-based material for bone tissue engineering. Stem Cells Int. 2015;2015:12.

25. Ilie I, Ilie R, Mocan T, Bartos D, Mocan L. Influence of nanomaterials on stem cell differentiation: designing an appropriate nanobiointerface. Int J Nanomedicine. 2012;7:2211-25.

26. Solanki A, Kim JD, Lee K-B. Nanotechnology for regenerative medicine: nanomaterials for stem cell imaging. Nanomedicine. 2008;3:567-78.

27. Zhao C, Tan A, Pastorin G, Ho HK. Nanomaterial scaffolds for stem cell proliferation and differentiation in tissue engineering. Biotechnol Adv. 2013; 31:654-68.

28. Goenka S, Sant V, Sant S. Graphene-based nanomaterials for drug delivery and tissue engineering. J Control Release. 2014;173:75-88.

29. Hubbell JA, Chilkoti A. Nanomaterials for drug delivery. Science. 2012;337:303.

30. Lock J, Liu H. Nanomaterials enhance osteogenic differentiation of human mesenchymal stem cells similar to a short peptide of BMP-7. Int J Nanomedicine. 2011;6:2769-77.

31. Li J, Zhang J, Wang X, Kawazoe N, Chen G. Gold nanoparticle size and shape influence on osteogenesis of mesenchymal stem cells. Nanoscale. 2016:8:7992-8007.

32. Li JEJ, Kawazoe N, Chen G. Gold nanoparticles with different charge and moiety induce differential cell response on mesenchymal stem cell osteogenesis. Biomaterials. 2015;54:226-36.
33. Yi C, Liu D, Fong C-C, Zhang J, Yang M. Gold nanoparticles promote osteogenic differentiation of mesenchymal stem cells through p38 MAPK pathway. ACS Nano. 2010;4:6439-48.

34. Grayson WL, Zhao F, Izadpanah R, Bunnell B, Ma T. Effects of hypoxia on human mesenchymal stem cell expansion and plasticity in 3D constructs. J Cell Physiol. 2006;207:331-9.

35. Martino MM, Mochizuki M, Rothenfluh DA, Rempel SA, Hubbell JA, Barker $\mathrm{TH}$. Controlling integrin specificity and stem cell differentiation in 2D and $3 \mathrm{D}$ environments through regulation of fibronectin domain stability. Biomaterials. 2009;30:1089-97.

36. Pek YS, Wan ACA, Ying JY. The effect of matrix stiffness on mesenchymal stem cell differentiation in a 3D thixotropic gel. Biomaterials. 2010;31:385-91.

37. Abdallah BM, Kassem M. Human mesenchymal stem cells: from basic biology to clinical applications. Gene Ther. 2007;15:109.

38. Sila-Asna M, Bunyaratvej A, Maeda S, Kitaguchi H, Bunyaratavej N. Osteoblast differentiation and bone formation gene expression in strontium-inducing bone marrow mesenchymal stem cell. Kobe J Med Sci. 2007:53:25-35.

39. Ng F, Boucher S, Koh S, Sastry KS, Chase L, Lakshmipathy U, Choong C, Yang Z, Vemuri MC, Rao MS. PDGF, TGF- $\beta$, and FGF signaling is important for differentiation and growth of mesenchymal stem cells (MSCs): transcriptional profiling can identify markers and signaling pathways important in differentiation of MSCs into adipogenic, chondrogenic, and osteogenic lineages. Blood. 2008;112:295-307.

40. Yoon D, Kim H, Lee E, Park MH, Chung S, Jeon H, Ahn C-H, Lee K. Study on chemotaxis and chemokinesis of bone marrow-derived mesenchymal stem cells in hydrogel-based 3D microfluidic devices. Biomater Res. 2016;20:25.

41. Bonab MM, Alimoghaddam K, Talebian F, Ghaffari SH, Ghavamzadeh A, Nikbin B. Aging of mesenchymal stem cell in vitro. BMC Cell Biol. 2006;7:14.

42. Yoshimura H, Muneta T, Nimura A, Yokoyama A, Koga H, Sekiya I. Comparison of rat mesenchymal stem cells derived from bone marrow, synovium, periosteum, adipose tissue, and muscle. Cell Tissue Res. 2007;327:449-62.

43. Akhavan O, Ghaderi E, Emamy H, Akhavan F. Genotoxicity of graphene nanoribbons in human mesenchymal stem cells. Carbon. 2013;54:419-31.

44. Chao T-I, Xiang S, Chen C-S, Chin W-C, Nelson A, Wang C, Lu J. Carbon nanotubes promote neuron differentiation from human embryonic stem cells. Biochem Biophys Res Commun. 2009;384:426-30.

45. Liu D, Yi C, Zhang D, Zhang J, Yang M. Inhibition of proliferation and differentiation of mesenchymal stem cells by carboxylated carbon nanotubes. ACS Nano. 2010;4:2185-95.

46. Akhavan O, Ghaderi E, Abouei E, Hatamie S, Ghasemi E. Accelerated differentiation of neural stem cells into neurons on ginseng-reduced graphene oxide sheets. Carbon. 2014;66:395-406.

47. Kim J, Choi KS, Kim Y, Lim KT, Seonwoo H, Park Y, Kim DH, Choung PH, Cho CS, Kim SY. Bioactive effects of graphene oxide cell culture substratum on structure and function of human adipose-derived stem cells. J Biomed Mater Res Part A. 2013;101:3520-30.

48. Weaver $\mathrm{CL}$, Cui XT. Directed neural stem cell differentiation with a functionalized graphene oxide nanocomposite. Adv Healthc Mater. 2015;4:1408-16.

49. Tehrani Z, Burwell G, Azmi MM, Castaing A, Rickman R, Almarashi J, Dunstan $P$, Beigi AM, Doak S, Guy O. Generic epitaxial graphene biosensors for ultrasensitive detection of cancer risk biomarker. 2D Mater. 2014;1:025004.

50. Elkhenany H, Amelse L, Lafont A, Bourdo S, Caldwell M, Neilsen N, Dervishi E, Derek O, Biris AS, Anderson D. Graphene supports in vitro proliferation and osteogenic differentiation of goat adult mesenchymal stem cells: potential for bone tissue engineering. J Appl Toxicol. 2015:35:367-74.

51. Lee JH, Shin YC, Jin OS, Kang SH, Hwang Y-S, Park J-C, Hong SW, Han D-W. Reduced graphene oxide-coated hydroxyapatite composites stimulate spontaneous osteogenic differentiation of human mesenchymal stem cells. Nano. 2015;7:11642-51.

52. Gu M, Liu Y, Chen T, Du F, Zhao X, Xiong C, Zhou Y. Is graphene a promising nano-material for promoting surface modification of implants or scaffold materials in bone tissue engineering? Tissue Eng Part B Rev. 2014:20:477-91.

53. Tatavarty R, Ding H, Lu G, Taylor RJ, Bi X. Synergistic acceleration in the osteogenesis of human mesenchymal stem cells by graphene oxide-calcium phosphate nanocomposites. Chem Commun. 2014;50:8484-7.

54. Suhito IR, Han Y, Kim D-S, Son H, Kim T-H. Effects of two-dimensional materials on human mesenchymal stem cell behaviors. Biochem Biophys Res Commun. 2017:493:578-84.

55. Chen G-Y, Pang D-P, Hwang S-M, Tuan H-Y, Hu Y-C. A graphene-based platform for induced pluripotent stem cells culture and differentiation. Biomaterials. 2012;33:418-27. 
56. Chen Y-S, Hung Y-C, Liau I, Huang GS. Assessment of the in vivo toxicity of gold nanoparticles. Nanoscale Res Lett. 2009;4:858.

57. Peer D, Karp JM, Hong S, Farokhzad OC, Margalit R, Langer R. Nanocarriers as an emerging platform for cancer therapy. Nat Nanotechnol. 2007;2:751.

58. Zhang L, Gu F, Chan J, Wang A, Langer R, Farokhzad O. Nanoparticles in medicine: therapeutic applications and developments. Clin Pharmacol Ther. 2008;83:761-9

59. Boisselier E, Astruc D. Gold nanoparticles in nanomedicine: preparations, imaging, diagnostics, therapies and toxicity. Chem Soc Rev. 2009;38:1759-82.

60. Zhang X. Gold nanoparticles: recent advances in the biomedical applications. Cell Biochem Biophys. 2015;72:771-5.

61. Yoo D, Lee D. Oligochitosan-stabilized photoluminescent gold nanoconstructs for optical bioimaging. Biomater Res. 2017;21:20

62. Dreaden EC, Austin LA, Mackey MA, El-Sayed MA. Size matters: gold nanoparticles in targeted cancer drug delivery. Ther Deliv. 2012;3:457-78.

63. Kong F-Y, Zhang J-W, Li R-F, Wang Z-X, Wang W-J, Wang W. Unique roles of gold nanoparticles in drug delivery, targeting and imaging applications. Molecules. 2017;22:1445.

64. Fratoddi I, Venditti I, Cametti C, Russo MV. How toxic are gold nanoparticles? The state-of-the-art. Nano Res. 2015:8:1771-99.

65. Choi SY, Song MS, Ryu PD, Lam ATN, Joo S-W, Lee SY. Gold nanoparticles promote osteogenic differentiation in human adipose-derived mesenchymal stem cells through the Wnt/ß-catenin signaling pathway. Int J Nanomedicine. 2015;10:4383.

66. Venkatesan J, Kim S-K. Chitosan composites for bone tissue engineering —an overview. Mar Drugs. 2010;8:2252.

67. Peschel D, Zhang K, Fischer S, Groth T. Modulation of osteogenic activity of BMP-2 by cellulose and chitosan derivatives. Acta Biomater. 2012;8:183-93.

68. Poudel B, Lim S-W, Ki H-H, Nepali S, Lee Y-M, Kim D-K. Dioscin inhibits adipogenesis through the AMPK/MAPK pathway in 3T3-L1 cells and modulates fat accumulation in obese mice. Int J Mol Med. 2014;34:1401-8.

69. Tang Q, Chen C, Zhang Y, Dai M, Jiang Y, Wang H, Yu M, Jing W, Tian W. Wnt5a regulates the cell proliferation and adipogenesis via MAPKindependent pathway in early stage of obesity. Cell Biol Int. 2018;42:63-74.

70. Habibovic P, Yuan H, van der Valk CM, Meijer G, van Blitterswijk CA, de Groot K. 3D microenvironment as essential element for osteoinduction by biomaterials. Biomaterials. 2005;26:3565-75.

71. Lobo SE, Livingston Arinzeh T. Biphasic calcium phosphate ceramics for bone regeneration and tissue engineering applications. Materials. 2010;3:815-26.

72. Rosa V, Zhang Z, Grande R, Nör J. Dental pulp tissue engineering in full-length human root canals. J Dent Res. 2013;92:970-5.

73. Miramond T, Corre P, Borget P, Moreau F, Guicheux J, Daculsi G, Weiss P. Osteoinduction of biphasic calcium phosphate scaffolds in a nude mouse model. J Biomater Appl. 2014;29:595-604.

74. Jäger $M$, Feser $T$, Denck $H$, Krauspe R. Proliferation and osteogenic differentiation of mesenchymal stem cells cultured onto three different polymers in vitro. Ann Biomed Eng. 2005;33:1319-32.

75. Rosa V, Della Bona A, Cavalcanti BN, Nör JE. Tissue engineering: from research to dental clinics. Dent Mater. 2012;28:341-8.

76. Chung T-H, Wu S-H, Yao M, Lu C-W, Lin Y-S, Hung Y, Mou C-Y, Chen Y-C, Huang D-M. The effect of surface charge on the uptake and biological function of mesoporous silica nanoparticles in 3T3-L1 cells and human mesenchymal stem cells. Biomaterials. 2007;28:2959-66.

77. Curran JM, Chen R, Hunt JA. The guidance of human mesenchymal stem cell differentiation in vitro by controlled modifications to the cell substrate. Biomaterials. 2006;27:4783-93.

78. Sundelacruz S, Levin M, Kaplan DL. Membrane potential controls adipogenic and osteogenic differentiation of mesenchymal stem cells. PLoS One. 2008; 3:e3737.

79. Benoit DS, Schwartz MP, Durney AR, Anseth KS. Small functional groups for controlled differentiation of hydrogel-encapsulated human mesenchymal stem cells. Nat Mater. 2008;7:816

80. Wang H, Kwok DT, Xu M, Shi H, Wu Z, Zhang W, Chu PK. Tailoring of mesenchymal stem cells behavior on plasma-modified polytetrafluoroethylene. Adv Mater. 2012;24:3315-24.

81. Crowder SW, Prasai D, Rath R, Balikov DA, Bae H, Bolotin Kl, Sung H-J. Threedimensional graphene foams promote osteogenic differentiation of human mesenchymal stem cells. Nano. 2013;5:4171-6.

82. Dong $X$, Wang $X$, Wang $L$, Song $H$, Zhang $H$, Huang W, Chen P. 3D graphene foam as a monolithic and macroporous carbon electrode for electrochemical sensing. ACS Appl Mater Interfaces. 2012;4:3129-33.
83. Li N, Chen Z, Ren W, Li F, Cheng H-M. Flexible graphene-based lithium ion batteries with ultrafast charge and discharge rates. Proc Natl Acad Sci. 2012; 109:17360-5.

84. Zhou G, Li L, Ma C, Wang S, Shi Y, Koratkar N, Ren W, Li F, Cheng H-M. A graphene foam electrode with high sulfur loading for flexible and high energy li-S batteries. Nano Energy. 2015;11:356-65.

85. Zhao Y, Liu J, Hu Y, Cheng H, Hu C, Jiang C, Jiang L, Cao A, Qu L. Highly compression-tolerant supercapacitor based on polypyrrole-mediated graphene foam electrodes. Adv Mater. 2013;25:591-5.

86. Akhavan O, Ghaderi E, Shirazian SA, Rahighi R. Rolled graphene oxide foams as three-dimensional scaffolds for growth of neural fibers using electrical stimulation of stem cells. Carbon. 2016;97:71-7.

87. McBeath R, Pirone DM, Nelson CM, Bhadriraju K, Chen CS. Cell shape, cytoskeletal tension, and RhoA regulate stem cell lineage commitment. Dev Cell. 2004;6:483-95.

88. Mathieu PS, Loboa EG. Cytoskeletal and focal adhesion influences on mesenchymal stem cell shape, mechanical properties, and differentiation down osteogenic, adipogenic, and chondrogenic pathways. Tissue Eng Part B Rev. 2012;18:436-44

89. Tercero JE, Namin S, Lahiri D, Balani K, Tsoukias N, Agarwal A. Effect of carbon nanotube and aluminum oxide addition on plasma-sprayed hydroxyapatite coating's mechanical properties and biocompatibility. Mater Sci Eng C Mater Biol Appl. 2009;29:2195-202.

90. Balani K, Anderson R, Laha T, Andara M, Tercero J, Crumpler E, Agarwal A. Plasma-sprayed carbon nanotube reinforced hydroxyapatite coatings and their interaction with human osteoblasts in vitro. Biomaterials. 2007:28:618-24.

91. Balani K, Chen Y, Harimkar SP, Dahotre NB, Agarwal A. Tribological behavior of plasma-sprayed carbon nanotube-reinforced hydroxyapatite coating in physiological solution. Acta Biomater. 2007;3:944-51.

92. Lee J-R, Ryu S, Kim S, Kim B-S. Behaviors of stem cells on carbon nanotube. Biomater Res. 2015;19:3.

93. Gao W, The chemistry of graphene oxide, Graphene oxide, Springer2015, pp. 61-95.

94. Xie Y, Li H, Zhang C, Gu X, Zheng X, Huang L. Graphene-reinforced calcium silicate coatings for load-bearing implants. Biomed Mater. 2014;9:025009.

95. Kang SM, Park S, Kim D, Park SY, Ruoff RS, Lee H. Simultaneous reduction and surface functionalization of graphene oxide by mussel-inspired chemistry. Adv Funct Mater. 2011;21:108-12.

96. Ghasemi-Mobarakeh L, Prabhakaran MP, Morshed M, Nasr-Esfahani MH, Baharvand H, Kiani S, Al-Deyab SS, Ramakrishna S. Application of conductive polymers, scaffolds and electrical stimulation for nerve tissue engineering. J Tissue Eng Regen Med. 2011;5:e17-35.

97. Gomez N, Lee JY, Nickels JD, Schmidt CE. Micropatterned polypyrrole: a combination of electrical and topographical characteristics for the stimulation of cells. Adv Funct Mater. 2007;17:1645-53.

98. Svennersten K, Larsson KC, Berggren M, Richter-Dahlfors A. Organic bioelectronics in nanomedicine. Biochim Biophys Acta Gen Subj. 2011; 1810:276-85.

99. Hsiao YS, Kuo CW, Chen P. Multifunctional graphene-PEDOT microelectrodes for on-chip manipulation of human mesenchymal stem cells. Adv Funct Mater. 2013;23:4649-56

100. Hsiao Y-S, Lin C-C, Hsieh H-J, Tsai S-M, Kuo C-W, Chu C-W, Chen P. Manipulating location, polarity, and outgrowth length of neuron-like pheochromocytoma (PC12) cells on patterned organic electrode arrays. Lab Chip. 2011;11:3674-80.

101. Kang E-S, Kim D-S, Suhito IR, Choo S-S, Kim S-J, Song I, Kim T-H. Guiding osteogenesis of mesenchymal stem cells using carbon-based nanomaterials. Nano Converg. 2017:4:2.

102. Guo W, Wang S, Yu X, Qiu J, Li J, Tang W, Li Z, Mou X, Liu H, Wang Z. Construction of a 3D rGO-collagen hybrid scaffold for enhancement of the neural differentiation of mesenchymal stem cells. Nano. 2016;8:1897-904. 